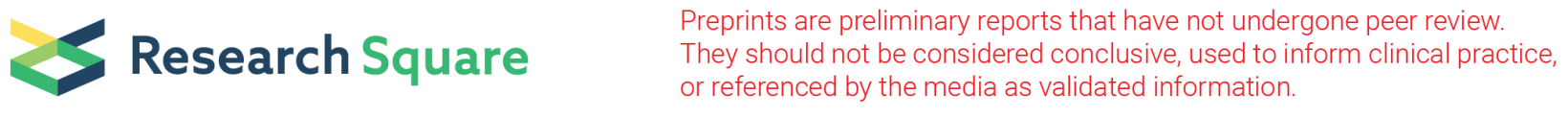

\title{
An innovative tubular standing support incorporating PVC and FRP composites: laboratory tests
}

\author{
Baisheng Zhang \\ Taiyuan University of Science and Technology \\ Hongchao Zhao ( $\nabla$ xjuzhc@163.com ) \\ University of Wollongong
}

\section{Research Article}

Keywords: Standing support, fibre-reinforced polymer, coal rejects, cementitious grout material

Posted Date: April 16th, 2021

DOI: https://doi.org/10.21203/rs.3.rs-379715/v1

License: 두 (i) This work is licensed under a Creative Commons Attribution 4.0 International License. Read Full License

Version of Record: A version of this preprint was published at Geotechnical and Geological Engineering on June 17th, 2021. See the published version at https://doi.org/10.1007/s10706-021-01895-9. 


\section{Abstract}

With the depletion of shallow resources, the drawbacks of conventional bolting system in sustaining the integrity of the roadway have drawn much attention. Developing the innovative secondary standing support is therefore to be urgent. This paper presents a hybrid tubular standing support, which consists of an exterior container made of PVC and fibre-reinforced polymer (FRP) composites and the infill material made of coal rejects and high flowable cementitious grout material. Compared with other marketable standing support, the combination application of the large rupture strain PVC tube and the FRP composite with high strength-to-weight ratio can provide the effective confinement to infill material, which may result in the strain hardening behaviour. The use of coal reject to generate the backfill material is believed to be effective and thus is attractive from the design aspect. To verify these mentioned advantages, a series of compression tests were conducted on this FRP-PVC tubular standing support (FPTSS) with different thickness of the FRP jacket. In addition, the compression tests were also conducted to investigate the compressive behaviour of FRP tubular standing support (FTSS) and PVC tubular standing support (PTSS). Test results indicated that the combination of FRP and PVC composite achieve the superior behaviour either in terms of the compressive strength or the deformation ability.

\section{Introduction}

Maintaining the integrity of rock surface for underground roadway is always the main concern for strata controlling engineers, the difficulty of which generally increases with the depletion of shallow coal resources [1-3]. It has been well noted either from the practice application or the theoretical foundation that conventional primary support techniques (e.g., rock bolt and cable bolt) cannot successfully prevent the serve deformation of surrounding rock for these roadways subjected to the complex geological conditions. With the increase of the mining depth, the surrounding rock of roadway tends to plastic from the elastic state. As a result, the uncontrolled deformation is believed to be the huge problem, because that the deformation ability of the cable bolt is generally limited. In addition, the underground water will also affect the effectiveness of the bolting system, in particularly, for the surrounding rock containing much water-sensitive components. Thus, it is impossible to maintain the integrity of the surrounding rock via the bolting system alone.

As a critical component of underground support systems, the significant importance of secondary standing support has therefore drawn much attention from coal operators [4-10]. Different from the bolting system, the main role of the secondary standing support is to provide additional resistance to surrounding rock, which is usually used together with the bolting system. These secondary standing support systems include the timber chock, concrete crib, l-sectional steel beam, concrete-filled steel tubular column (CFST), Can ${ }^{\circledR}$ support [11-12] and the pumpable standing support [13] and the. These secondary support systems can be divided into two groups according to their structural form. One is the structure made of one material (e.g., timber, concrete, steel, etc) and the other one is the composite structures made of more than two materials such as the CFST and the Can ${ }^{\circledR}$ support. Compared with its counterparts, these composite structures always obtain a high performance due to the combination effect. Taking the Can ${ }^{\circledR}$ support for example, the concrete core was confined by the exterior steel container and the concrete core is in the tri-axial state. As a result, both the axial deformation and the compressive strength of the concrete core has been significantly enhanced. In addition, the inner buckling of the exterior steel tube can be prevented when it is filled with concrete.

Although the $\mathrm{Can}^{\circledR}$ support is believed to be the most stable secondary standing support in the market, there are still some drawbacks to be tackled with [11-12]. One is that the heavy duty of the steel container, which may significantly affect the normal transportation and increase the investment for coal operators from the application aspect. In addition, the long-distance transportation of the infill material is also the other concern. Moreover, the confining pressure provided by the exterior steel tube will be constant, once the buckling of the steel tube occurred (see Figure 1). As a result, the load carrying capacity of the $\mathrm{Can}^{\circledR}$ support will experience the unexpected decline, which is not allowed from the design aspect.

Recently, the conceptual standing support incorporating fibre-reinforced polymer (FRP) composite and waste lump filled backfill (LFB) material has been proposed at the University of Wollongong [15-17]. The main feature of this FRP tubular standing support (FTSS) is that the exterior container is made of FRP composite with high strength-to-weight ratio, whereas the lump-filled backfill (LFB) material made of coarse lumps and high flowable cementitious grout material. The preliminary tests have demonstrated the high performance of this conceptual standing support and the feasibility of the utilization of coal rejects being the coarse lumps. Compared with market available standing supports, FTSS presents a typical strain hardening behaviour. However, the brittleness of FRP composite restricts the axial deformation ability of this FRP tubular column. Once the limited tensile rupture strain of FRP composite is reached, the load shedding events will be then occurred, which is not suitable to deep mining applications. 
To further enhance the performance of FTSS, this paper introduces a hybrid standing support incorporating the PVC and fibre-reinforced polymer (FRP) composite. For ease of reference, this modified standing support is termed as FRP-PVC tubular standing support (FPTSS) hereafter. As depicted in Figure 2, the main feature of this innovative structural form is its exterior made of PVC with large rupture strain and FRP with high strength-to-weight ratio rather than the steel. Compared with the steel container in the Can ${ }^{\circledR}$ support, both the PVC and FRP composites are with light weight, which is expected to reduce the total weight of the standing support. In addition, the linear elastic tensile behaviour of the FRP composites can make sure the confining pressure applied on the infill material keeps increasing until the rupture of the exterior FRP composite. In this case, this hybrid support may exhibit the strain-hardening behaviour under compression. Most importantly, the inner PVC tube may sustain the integrity of the structural form after the rupture of the exterior FRP jacket, the axial deformation of which is expected to be comparative to the Can ${ }^{\circledR}$ support.

Except for the simple change of the exterior container, the infill material of this hybrid support will also bring some attractive advantages. As illustrated in Figure 2, the coal rejects (i.e. typical industry by-product generated from the coal process) and high flowable cementitious grout material are combined together to be the infill material. Different from coal rejects concrete, the cementitious grout material is directly injected into the lumped coal rejects without the specific mixture process. With the development of the coal rejects separation system, the coal rejects can be easily obtained from underground space and thus only the cementitious grout material is requested. Different from other market available product, the cementitious grout material stated herein is the CSA based material. Due to the high water-to-powder ratio, only a little bit material is requested because most of the solid infill is underground water. With the use of the high flowable cementitious grout material, the voids between nun-uniformly distributed coal rejects can be easily filled.

To verify the expected compressive performance of the FPTSS, a series of compression tests covering the thickness of FRP composites have been conducted. In addition, the compressive behaviours of FTSS and PVC tubular standing support (i.e. PTSS) were compared with FPTTSS, respectively.

\section{Experimental Programme}

\subsection{Tested specimens}

As listed in Table 1, a total of 13 tubular specimens have been prepared and tested, including 3 LFB specimens without confinement, 2 PTSS specimens, 2 FTSS specimens and 6 FPTSS specimens. For these specimens with the exterior containers, there are two identical specimens in each group. Note that all specimens had an inner diameter of $100 \mathrm{~mm}$ and a height of $200 \mathrm{~mm}$. For these specimens with the FRP jacket, the 100-mm-length overlapping zone was applied to prevent the unexpected debonding. For ease of reference, each specimen was given a name, starting with the short name of the columns. The followed number is used to represent the ply of the FRP jacket. The last Roman number is used to differentiate two or three nominally identical specimens from each other. Taking FPTSS-2-II for example, it is the second FPTSS specimen covered with a 2-ply FRP jacket.

\subsection{Material properties}

Coal rejects used in this research was provided by the local coal mines located at the New South Wales in Australia, more detailed information about the mechanical and physical properties of which can be seen from the reference. Herein, the coal rejects with the nominal particle size of $10 \mathrm{~mm}$ were adopted. The results of sieving analysis can be found from Figure 3. It is apparent that these coal rejects share the relatively constant particle size distribution.

The cementitious grout material (CMT) provided by Minova Australia was adopted to generate the slurry. According to the technical data sheet provided by the supplier, the main content of CMT grout material is the CSA cement. In addition, the gypsum and quick lime are also added to control the setting time. Table 2 presents the mechanical properties of CMT grout material. As can be seen from Table 2, the largest water-to-powder ratio can be 2.0 , for which the utilization of the cementitious grout material will be consequently reduced.

\subsubsection{FRP and PVC composite}

Tensile tests on six FRP coupons and PVC coupons were conducted in accordance with ASTM-D3039/D3039M [18]. The test results showed that the average tensile stress of FRP composite based on a nominal thickness of $0.17 \mathrm{~mm}$ per ply is $1129.8 \mathrm{MPa}$, which is about 22 times of that of PVC with the average of tensile stress (51.6 MPa) calculated based on the nominal thickness (3.0 mm). 
However, the rupture strain of FRP composite averaged from six flat coupons $(1.4 \%)$ is much smaller than that of PVC coupons with the average value of $45.7 \%$. It is expected that the PVC tube can still sustain the structural form after the failure of the exterior FRP jacket with limited rupture strain in tension.

Two hollow PVC tubes, FRP tubes as well as the FRP-PVC tubes were tested to investigate their compressive behaviour. Herein, the length of these tubes is $100 \mathrm{~mm}$, which are the same as the overall height of tested specimens with infill material. The average load carrying capacities of these tubes are listed in Table 1, from which it can be found that the maximum load capacities of FRP-PVC tube increase with the FRP thickness.

\subsection{Preparation of specimens}

The preparation of FPTSS consists of the flowing steps: (1) fixing the hollow PVC tube on the water-proof wooden base (Figure 4a); (2) filling the fixed hollow PVC tube with coal rejects (Figure 4b); (3) mixing the CMT grout material with requested water and then dumping the mixed slurry into the lumped coal rejects (Figure 4c); (4) cutting E-glass fibre sheet with requested length (Figure 4d); and (5) embedding the fibre sheet into the epoxy resin to generate the FRP composite and then wrapping the FRP jacket on the surface of the PVC tube (Figure 4e). Note that only steps (1)-(3) are requested for preparation of LFB specimens, FTSS specimens and PTSS specimens. For LFB specimens and FTSS specimens, the inner backfill material was obtained by removing the exterior PVC tube after 3 days for curing. Then, the FRP jacket was wrapped on the surface of the LFB specimen by the wet-layup procedure. Note that the 100mm-length overlapping zone of FRP jacket was left to prevent the debonding for these specimens incorporating FRP composites.

\subsection{Test set-up and instruments}

All specimens were tested on the 500-tones compression machines with the displacement control. Except for LFB specimens which was tested with the speed of $0.6 \mathrm{~mm} / \mathrm{min}$, the same displacement rate of $1.5 \mathrm{~mm} / \mathrm{min}$ was adopted for other specimens with the confining container. As shown in Figure 5, two linear variable displacement transducers (LVDTs) were placed at the opposite corners on the bottom loading plate to measure the overall axial shortening of all specimens. The Cannon camera was set up in front of the specimens to record the progressive failure process of specimens. All data including the axial load and the axial displacements were recorded by a data logger simultaneously.

\section{Results And Discussions}

\subsection{Failure modes}

It is apparent that in Figure 6 that these three LFB specimens are all with the typical shear failure modes. In detail, only limited fresh failure surface observed from the coal rejects. A large amount of the obvious separation was found from the interface between the coal rejects and the cementitious grout material, indicating that the interface is the weakest zone for LFB material.

Different from LFB specimens without any confinement, all FPTSS specimens failed by the rupture of exterior FRP composite under hoop tension (see Figures 7a-c). There were some white cracks before the final rupture of FRP jacket associated with the loud noise. After the failure of the exterior FRP jacket, the structural form can still sustain somewhat axial load until the large axial shortening. Without the confinement provided by the FRP jackets, the axial load experiences the sharply decline from the peak load to the low level, which can be found from the axial load-axial shortening curves shown in Figure 7 as well. During this period, the inner PVC tube experience the outward buckling until the large axial shortening. When the exterior FRP-PVC tube was removed, it can be found that there were some cracks observed from the coal rejects.

For FTSS specimen presented in Figure 8, the exterior FRP tube in FTSS specimen experienced a rupture under tension associated with a sudden load shedding event. Whereas, the serve buckling of exterior PVC tube were observed in Figure 9.

\subsection{Axial load-axial shortening behaviour}

The key results of all tested specimens are listed in Table 1, in which the axial loads of LFB specimens and exterior container averaged from two or three identical specimens were termed as $P_{\text {infill }}$ and $P_{\text {exterior, }}$ respectively. The peak axial load of FPTSS specimen, PTSS 
specimen and FTSS specimens was denoted as $P_{\text {total }}$. The axial shortening corresponding to the peak axial load was denoted as $S_{\text {total }}$. $P_{\text {infill }}+P_{\text {exterior }}$ represents the ultimate load of constitute material regardless of the possible difference attributed to the combined effect of different materials. Then, $₫ P_{\text {total }}-P_{\text {exterior }} \otimes /\left(P_{\text {infill }}\right)$ was adopted to represent the enhancement of load carrying capacity of LFB material with confinement. The axial shortening of LFB specimens corresponding to the peak load $P_{\text {infill }}$ is denoted as $S_{\text {infill, }}$, and $S_{\text {total }} /$ $S_{\text {infill }}$ presented in Table 1 indicates the enhancement of ductility of confined LFB material in different specimens.

The axial load-axial shortening curves of unconfined LFB specimens are plotted in Figure 6, in which the axial shortening was averaged from these two LVDT installed on the loading platens of the compression machine. The constant axial load-axial shortening curves of LFB specimens obtained from three identical specimens indicate that the preparation of LFB specimens with non-uniform distributed coal rejects is reliable and reasonable. As mentioned earlier, the axial load will experience the sharply decline due to the development of failure occurred around the interface between the coal reject and cementitious grout material. Once the peak load was reached, the integrity of the material will be significantly affected. It is thus believed that the LFB cannot be directly used as a secondary standing support.

Figures 7 present the compressive behaviour of FPTSS specimens with different thickness of FRP jacket. Compared with these unconfined LFB specimens, all FPTSS specimens achieved a large axial shortening, not only in terms of the axial shortening at the peak axial load, but also the ultimate axial shortening (> $60 \mathrm{~mm}$, equivalent to $30 \%$ of the overall height of the specimen).

As shown in Figure 7, the axial load-axial shortening curves of FPTSS specimens can be divided into three portions: (1) ascending part with a bilinear shape; (2) sudden load shedding part with a linear shape; and (3) slight ascending part with minor fluctuations. The transition point between the first portion and the second portion corresponds to the rupture of FRP composite which were observed from the testing procedure. It is not difficulty to explain the specific behaviour of FPTSS specimens under compression. As mentioned above, the FRP-PVC container will not act as the container for ease of construction but also provide confining pressure to infill material. In this case, the infill material is under the tri-axial state and the behaviour of which will be closely related to the confining action of the exterior device. At the beginning of the test, the axial load of FPTSS was initially resisted by the infill material and the exterior FRP-PVC tube. With the increasing lateral expansion of infill material, the confining pressure provided by the FRP-PVC container leads to the ascending prat of the axial load-axial shortening curves. This process will last for a long time until the rupture of the exterior FRP jacket associated with the sudden load shedding. Then, the confining pressure acting on the infill material is mainly from the PVC tube and the residual FRP jacket apart from the ruptured zone. More detailed discussion on the confining action of FRP-PVC container on infill material can be found from the following section.

\subsection{Comparison between FPTSS and FTSS specimens}

As can be seen from the preparation procedure of the FPTSS specimen, the only difference between FPTSS specimen and FTSS specimen is the former of which contains the additional PVC tube. Therefore, it is believed that the difference between the compressive behaviour of these specimens is mainly attributed to the existence of the PVC tube. To verify the above conclusion, the axial load-axial shortening curves of these specimens are depicted in Figure 8, in which all these specimens had a 3-ply FRP jacket. In addition, the plain LFB specimens without confinement was also plotted in Figure 8 for comparison.

It is apparent that the axial peak loads of FPTSS specimens are higher than that of FTSS specimens, mainly attributed to the additional use of PVC tube in resisting somewhat axial load. As listed in Table 1, the sum of the axial load resisted by the hollow PVC tube and the FTSS is approximately equal to the axial load of FPTSS, which can be regarded as the other evidence to support above assumption.

The other attractive observation obtained from the above comparison is the axial deformation ability of the FPTSS specimen is much superior than its counterparts. As shown in Figure 8, the average axial load of FPTSS specimens is about $125 \mathrm{kN}$ (equal to $50 \%$ of the peak load) corresponding to the large axial deformation (i.e. $80 \mathrm{~mm}$ ). However, the axial deformation of FTSS is only $40 \mathrm{~mm}$ when the axial load reduced to $50 \%$ of the peak load. This comparative advantage indicates that the effect of the PVC tube is not only increase the axial load carrying capacity but also enhance the axial deformation ability.

\subsection{Comparison between FPTSS and PTSS specimens}

Page 5/13 
The axial load-axial curves of FPTSS specimens and PTSS specimens are plotted together in Figure 9 to investigate the effect of FRP jacket on the compressive behaviour of FPTSS specimens. As mentioned above, the only difference between the FPTSS specimens and PTSS specimens herein is the additional FRP jackets. It is thus feasible to obtain the understanding of the contribution provided by the FRP jacket.

It is evident that the peak axial loads of FPTSS specimens are larger than that of corresponding PTSS specimens. As can be seen from Table 1, the peak axial loads of FPTSS specimens are still higher than that of PTSS specimens when the axial load resisted by FRP composite was excluded. This observation suggests that the enhancement of load carrying capacity of FPTSS specimens is attributed to the confining action of exterior FRP jacket. Different from PVC tube, the linear tensile behaviour of FRP jacket will result int the increasing confining action applied on the infill material and the infill material will be under the tri-axial state. If the confining pressure acted on the infill material is large enough, the axial load-axial shortening curves of confined material will be thus in the manner of strain hardening. Even though, the tensile rupture strain of FRP composite is generally smaller than that of these PVC tube. As a result, the axial load of FPTSS will not sustain a high value for a long time. Due to the large rupture strain of PVC tube, the axial load carrying capacity of FPTSS specimen will not decline to an extremely low level after the occurrence of the FRP rupture. In addition, the residual FRP jacket apart from the rupture zone will also provide somewhat confining pressure, resulting in the slightly increasing of the axial load at the large axial shortening.

Different from the obvious enhancement of the load carrying capacity, the effect of the utilization of FRP jacket in enhancing the deformation ability is limited. As seen from Figure 9, there is no significant enlargement of the axial shortening when these two types of structural forms are compared. Because that the rupture strain of FRP jacket is much smaller than that of PVC tube in tension, the large deformation ability of FPTSS specimens is mainly attributed to PVC tube rather than the exterior FRP jacket.

\section{Conclusions}

This paper presents a novel FRP-PVC tubular standing support (FPTSS) for underground mines. The main feature of FPTSS is that the exterior container is the combination of polyvinyl chloride with large tensile rupture strain and the fibre-reinforced polymer (FRP) with high tensile strength, while the infill is made of coal rejects and high flowable cementitious grout material. Compared to its counterparts, FPTSS is believed to be cost effective and environment friendly. To obtained an in-depth understanding of this composite structure, a series compression tests were conducted. The following conclusions can be drawn based on the discussions of the experimental tests:

(1) Different from the unconfined LFB material, the combination of three components (i.e. PVC, FRP and LFB) in FPTSS leads to the significantly enhancement of the load carrying capacity and the deformation ability;

(2) The FPTSS incorporating FRP-PVC container obtained a superior compressive performance: an approximate bilinear axial load-axial shortening curves characteristics with a strain hardening behaviour, followed by a slight ascending portion after the load shedding event;

(3) Compared with FTSS specimens, the PVC tube with large rupture strain in FPTSS sustains the large axial deformation after the rupture of FRP composite. Compared with PTSS specimens, the high strength-to-weight ratio of FRP composite in FPTSS contribute to the significant enhancement of the load carrying capacity.

Note that the main aim of this paper is to obtain a first insight on the compressive behaviour of the alternative to the Can ${ }^{\circledR}$ support, namely FPTSS support system. Therefore, only limited number of small-scale specimens were prepared and tested. From the design aspect, the systematic research covering the large range of critical parameters such as the type of FRP composite, the thickness of PVC tube as well as the sources of coal rejects, etc should be well investigated before the trial tests in practical application.

\section{Declarations}

Funding: National Natural Science Foundation of China (No. 51904268), the Australia Coal Industry's Research Program (C28068) and the Key Research Programme (high-tech) of Shanxi Province (201903D121075)

Conflicts of interest/Competing interests: Not applicable

Availability of data and material: Not applicable

Code availability: Not applicable

Page 6/13 


\section{Acknowledgement}

The authors of this paper would like to thank the National Natural Science Foundation of China (No. 51904268) and the Australia Coal Industry's Research Program (C28068) for their finical support. The first author also wishes to thank the University of Wollongong for the financial support for his PhD study in Australia.

\section{References}

1. Ghorbani M, Shahriar K, Sharifzadeh M, Masoudi R, A critical review on the developments of rock support systems in high stress ground conditions, International Journal of Mining Science and Technology (2020)

2. Peng SS (2015) Topical areas of research needs in ground control-a state of the art review on coal mine ground control. International Journal of Mining Science Technology 25(1):1-6

3. Qiao Q, Nemcik J, Porter I, Baafi E (2015) Laboratory tests on thin spray-on liner penetrated rock joints in direct shear. Rock Mech Rock Eng 48(5):2173-2177

4. Kang H, Lv H, Zhang X, Gao F, Wu Z, Wang Z (2016) Evaluation of the ground response of a pre-driven longwall recovery room supported by concrete cribs. Rock Mech Rock Eng 49(3):1025-1040

5. Kang H (2014) Support technologies for deep and complex roadways in underground coal mines: a review. International Journal of Coal Science Technology 1(3):261-277

6. Li Y, Li K, Feng X, Cai M (2018) Development and evaluation of artificial expandable pillars for hard rock mining. Int J Rock Mech Min Sci 110:68-75

7. Tai Y, Xia H, Liu H, Ma Z, Zhang Y, Control for the large section roadway under small abandoned mines in the same coal seam by secondary support, Energy Science \& Engineering

8. Yu K, Ren F, Puscasu R, Lin P, Meng Q (2020) Optimization of combined support in soft-rock roadway. Tunn Undergr Space Technol 103:103502

9. Batchler T (2017) Analysis of the design and performance characteristics of pumpable roof supports. International Journal of Mining Science Technology 27(1):91-99

10. Zhao H (2019) State-of-the-art of standing supports for gob-side entry retaining technology in China. J South Afr Inst Min Metall 119(11):891-906

11. Shook MT, Sindelar MF, Jiang H, Luo Y (2017) Quantification of ventilation enhancement using the Eye CAN roof support. International Journal of Mining Science Technology 27(1):153-158

12. BARCZAK TM, TADOLINI SC (2005b) Standing support alternatives in western longwalls. National Institute for Occupational Safety and Health, Salt Lake City, 1-10

13. HUANG W-P, YUAN Q, TAN Y, WANG J, LIU G, QU G, LI C (2018) An innovative support technology employing a concrete-filled steel tubular structure for a 1000-m-deep roadway in a high in situ stress field. Tunn Undergr Space Technol 73:26-36

14. BARCZAK TM, CHEN J, BOWER J Pumpable roof supports: developing design criteria by measurement of the ground reaction curve. Proceedings, 22nd international conference on ground control in mining, Morgantown, WV (2003b) $283-93$

15. Zhao H, Ren T, Remennikov A (2021) Standing support incorporating FRP and high water-content material for underground space. Tunn Undergr Space Technol 110:103809

16. Zhao H, Ren T, Remennikov A (2021) Behaviour of FRP-confined coal rejects based backfill material under compression. Constr Build Mater 268:121171

17. Zhao H, Ren T, Remennikov A (2021) A hybrid tubular standing support for underground mines: Compressive behaviour. International Journal of Mining Science Technology 31(2):215-224

18. ASTM-D3039/D3039M (2017) Standard test method for tensile properties of polymer matrix composite materials. American Society for Testing and Materials, West Conshohocken

\section{Tables}

\section{Table 1 Test matrix and key results}




\begin{tabular}{|c|c|c|c|c|c|c|c|c|c|c|c|}
\hline \multirow[t]{2}{*}{ Series } & \multirow[t]{2}{*}{ Specimens } & \multirow[t]{2}{*}{$\begin{array}{l}\text { Infilled } \\
\text { material }\end{array}$} & \multicolumn{2}{|l|}{$\begin{array}{l}\text { Confining } \\
\text { material }\end{array}$} & \multirow[t]{2}{*}{$\begin{array}{l}P_{\text {infill }} \\
(\mathrm{kN})\end{array}$} & \multirow[t]{2}{*}{$\begin{array}{l}P_{\text {exterior }} \\
(\mathrm{kN})\end{array}$} & \multirow[t]{2}{*}{$\begin{array}{l}P_{\text {total }} \\
(\mathrm{kN})\end{array}$} & \multirow[t]{2}{*}{$\begin{array}{l}\left(\mathrm{P}_{\text {total }}{ }^{-}\right. \\
\left.\mathrm{P}_{\text {exterior }}\right) / \mathrm{P}_{\text {infill }}\end{array}$} & \multirow[t]{2}{*}{$\begin{array}{l}S_{\text {infill }} \\
(\mathrm{mm})\end{array}$} & \multirow[t]{2}{*}{$\begin{array}{l}S_{\text {total }} \\
(\mathrm{mm})\end{array}$} & \multirow[t]{2}{*}{$S_{\text {total }} / S_{\text {infil }}$} \\
\hline & & & Type & $\begin{array}{l}\text { No. } \\
\text { FRP } \\
\text { layer }\end{array}$ & & & & & & & \\
\hline \multirow[t]{3}{*}{1} & LFB-I & \multirow[t]{13}{*}{ LFB } & \multirow[t]{3}{*}{ I } & \multirow[t]{3}{*}{ / } & \multirow[t]{13}{*}{13.10} & \multirow[t]{3}{*}{0.00} & 13.89 & \multirow[t]{3}{*}{ / } & \multirow[t]{13}{*}{1.14} & / & / \\
\hline & LFB-II & & & & & & 13.19 & & & & \\
\hline & LFB-III & & & & & & 12.22 & & & & \\
\hline \multirow[t]{2}{*}{2} & PTSS-I & & \multirow[t]{2}{*}{ PVC } & \multirow[t]{2}{*}{ I } & & \multirow[t]{2}{*}{51.85} & 90.23 & 2.93 & & 6.56 & 5.75 \\
\hline & PTSS-II & & & & & & 89.35 & 2.86 & & 6.17 & 5.41 \\
\hline \multirow[t]{2}{*}{3} & FTSS-3-I & & \multirow[t]{2}{*}{ FRP } & \multirow[t]{2}{*}{3} & & \multirow[t]{2}{*}{16.48} & 178.98 & 12.40 & & 25.16 & 22.07 \\
\hline & FTSS-3-II & & & & & & 155.67 & 10.63 & & 24.57 & 21.55 \\
\hline \multirow[t]{6}{*}{4} & FPTSS-2-I & & \multirow[t]{6}{*}{$\mathrm{PVC}+\mathrm{FRP}$} & \multirow[t]{2}{*}{2} & & \multirow[t]{2}{*}{58.67} & 189.48 & 9.99 & & 15.05 & 13.20 \\
\hline & FPTSS-2-II & & & & & & 188.58 & 9.92 & & 14.54 & 12.75 \\
\hline & FPTSS-3-I & & & \multirow[t]{2}{*}{3} & & \multirow[t]{2}{*}{67.54} & 233.39 & 12.66 & & 15.73 & 13.80 \\
\hline & FPTSS-3-II & & & & & & 202.48 & 10.30 & & 12.77 & 11.20 \\
\hline & FPTSS-4-I & & & \multirow[t]{2}{*}{4} & & \multirow[t]{2}{*}{75.12} & 255.66 & 13.78 & & 13.92 & 12.21 \\
\hline & FPTSS-4-I & & & & & & 237.28 & 12.38 & & 9.68 & 8.49 \\
\hline
\end{tabular}

Table 2 Physical and mechanical properties of CMT grout

\begin{tabular}{|llllll|}
\hline \multirow{2}{*}{ Water-to-powder ratio } & \multicolumn{3}{l}{ UCS $(\mathrm{MPa})$} & Gel time $(\mathrm{min})$ & Fresh wet density $(\mathrm{kg} / \mathrm{m} 3)$ \\
\cline { 2 - 5 } & 1 days & 7 days & 28 days & \\
\hline 1.0 & 10.0 & 14.0 & 18.0 & $4-7$ & 1470.0 \\
\hline 1.5 & 6.0 & 8.0 & 12.5 & $9-11$ & 1340.0 \\
\hline 2.0 & 4.0 & 5.0 & 7.0 & $12-15$ & 1260.0 \\
\hline
\end{tabular}

\section{Figures}

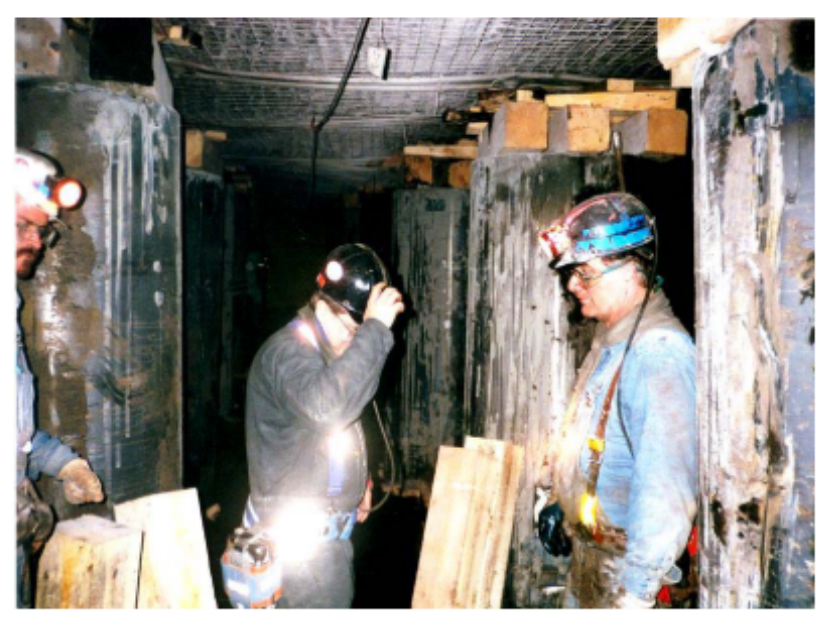

Figure 1 


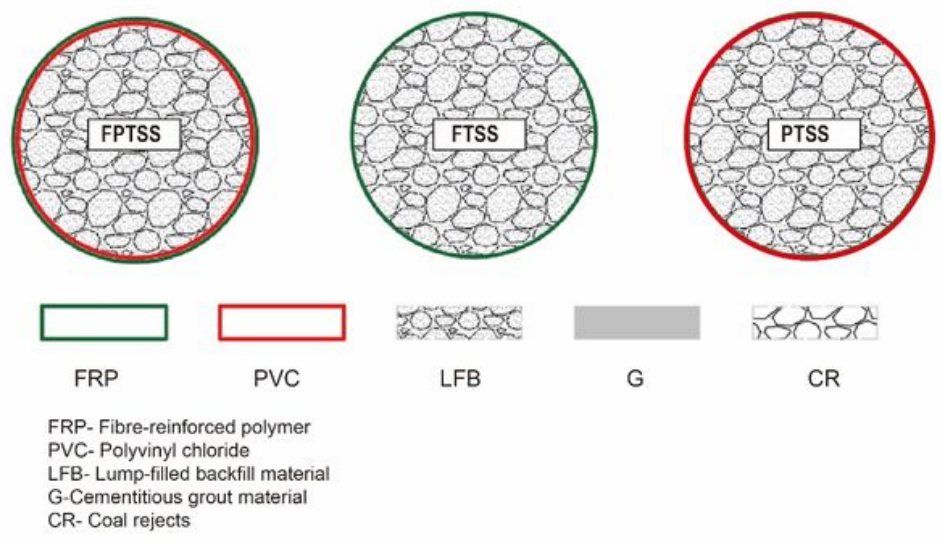

Figure 2

Cross section of the FPTSS support system

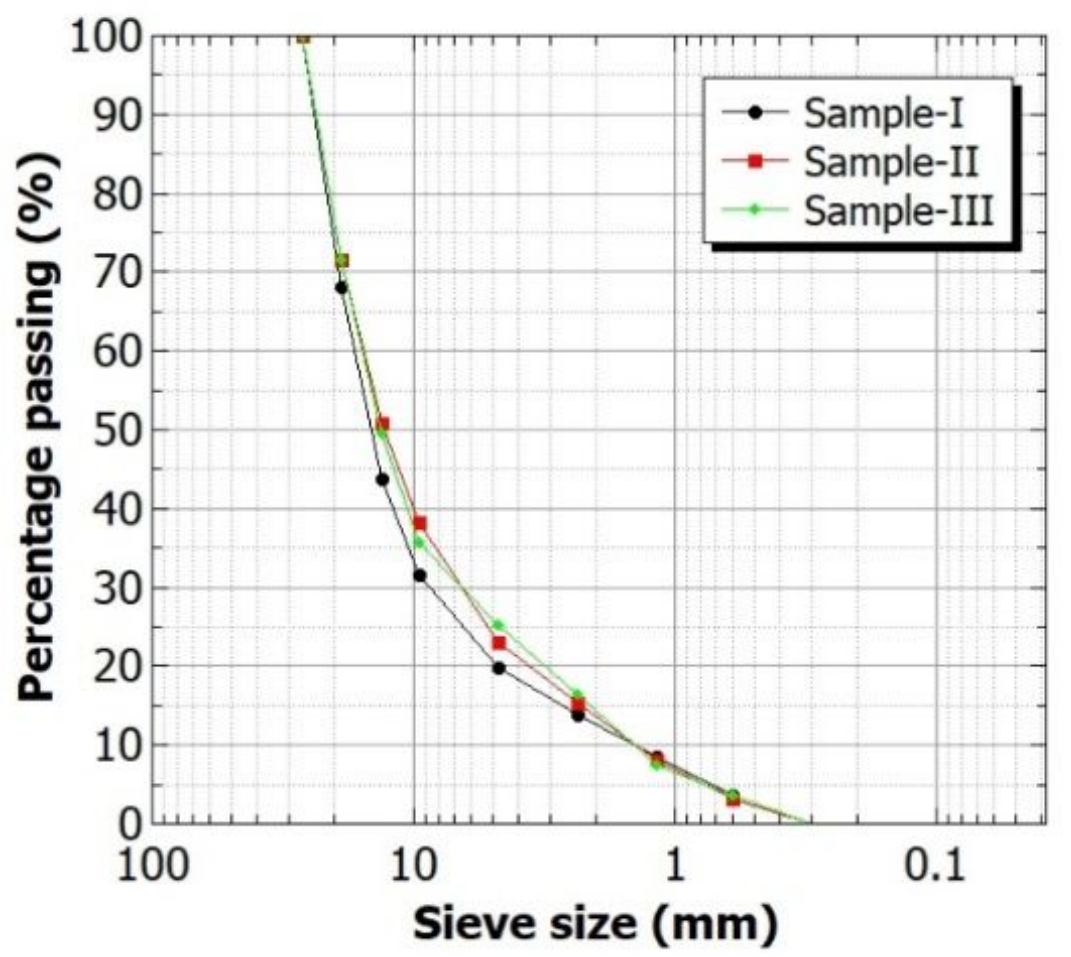

Figure 3 


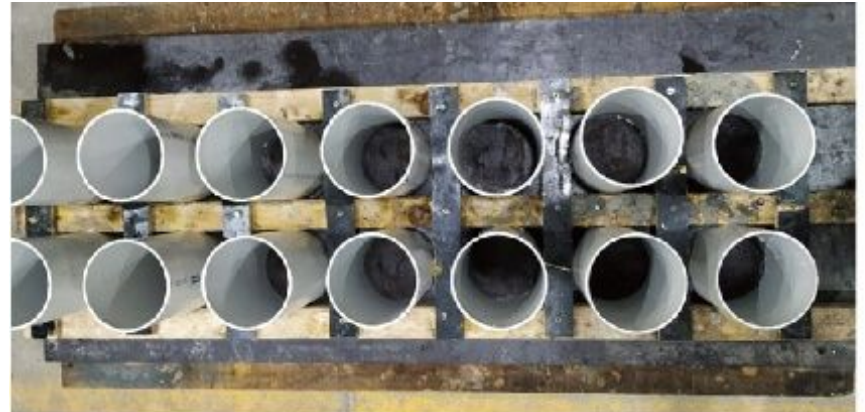

(a)

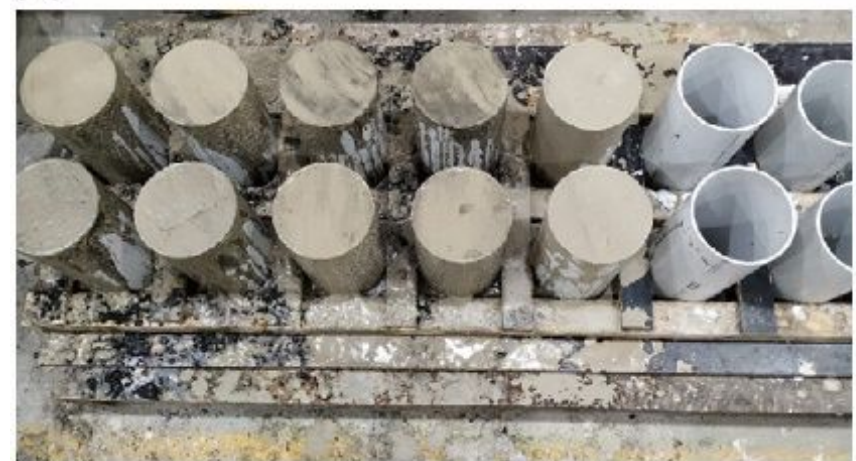

(c)

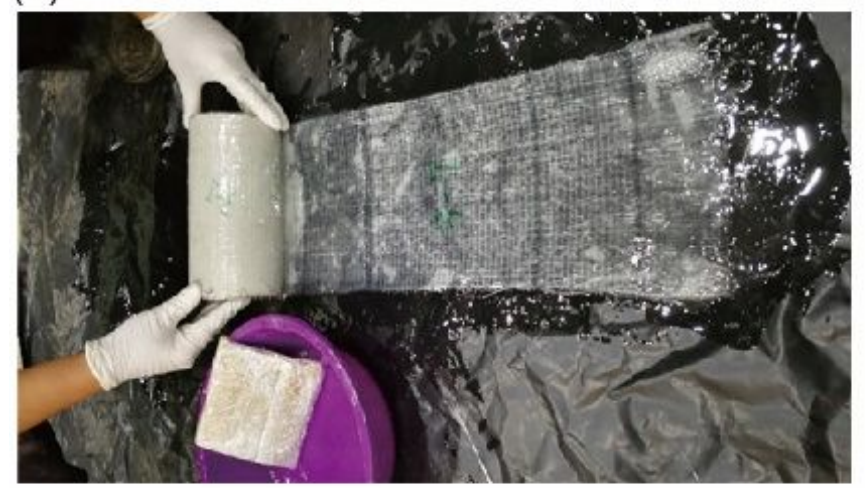

(e)

\section{Figure 4}

Preparation of specimens

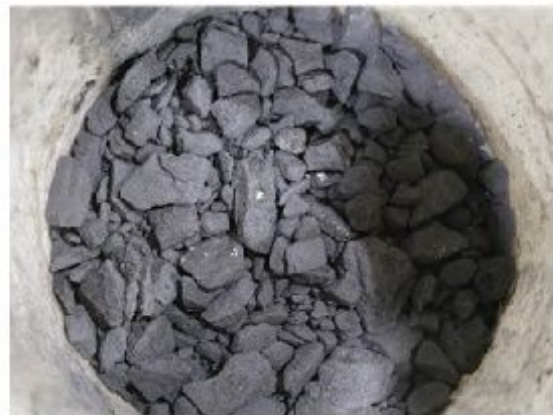

(b)

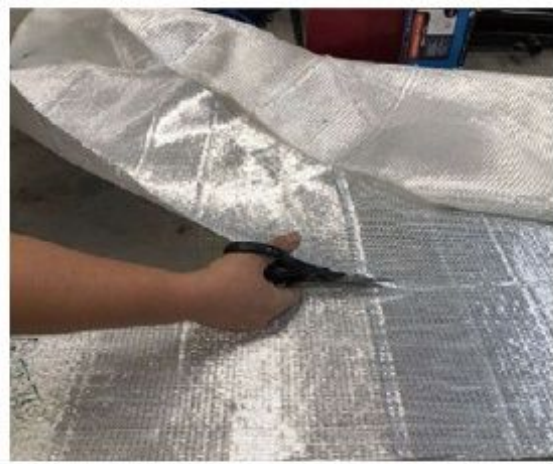

(d) 


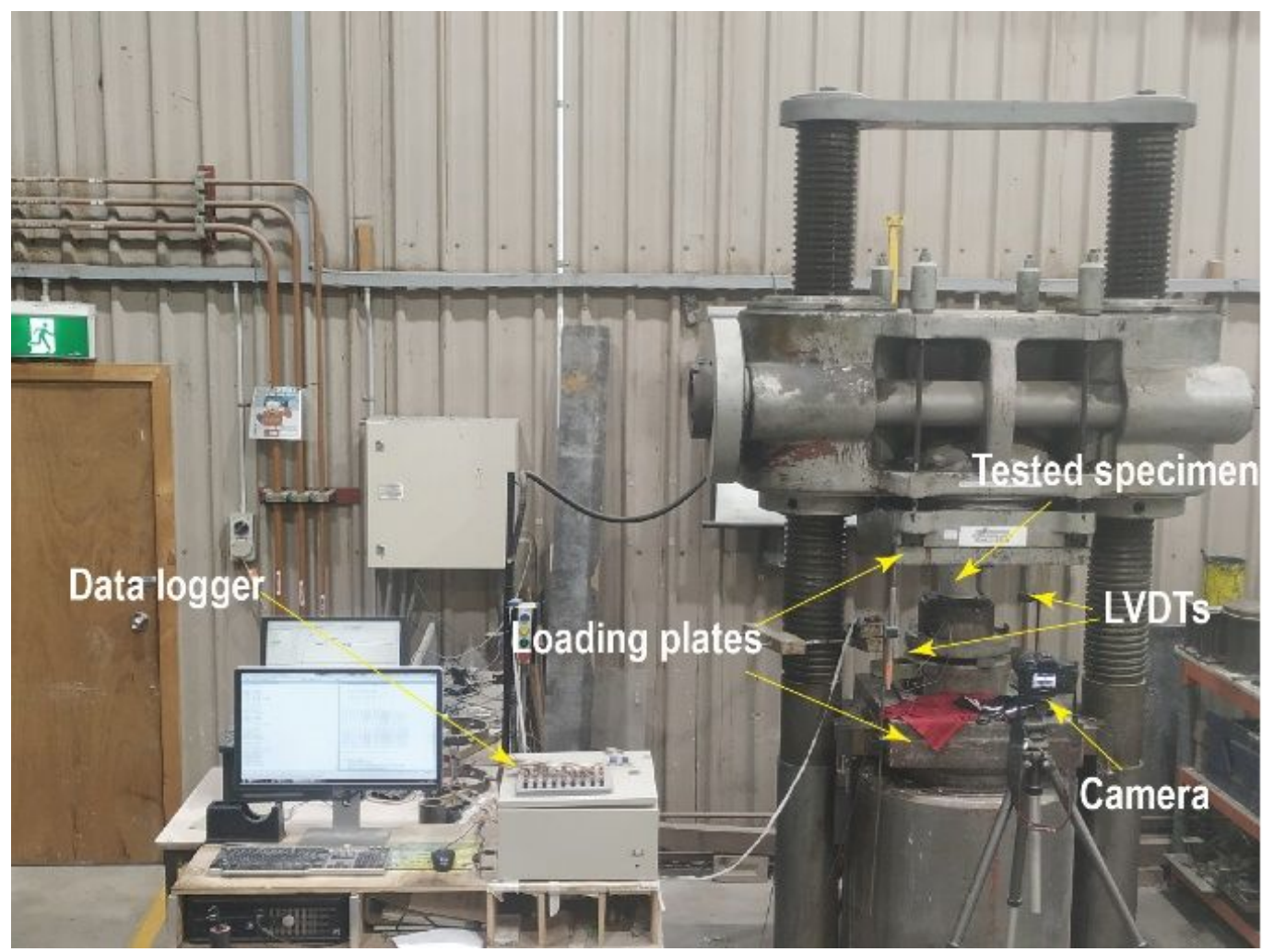

Figure 5

Test set-up and instruments

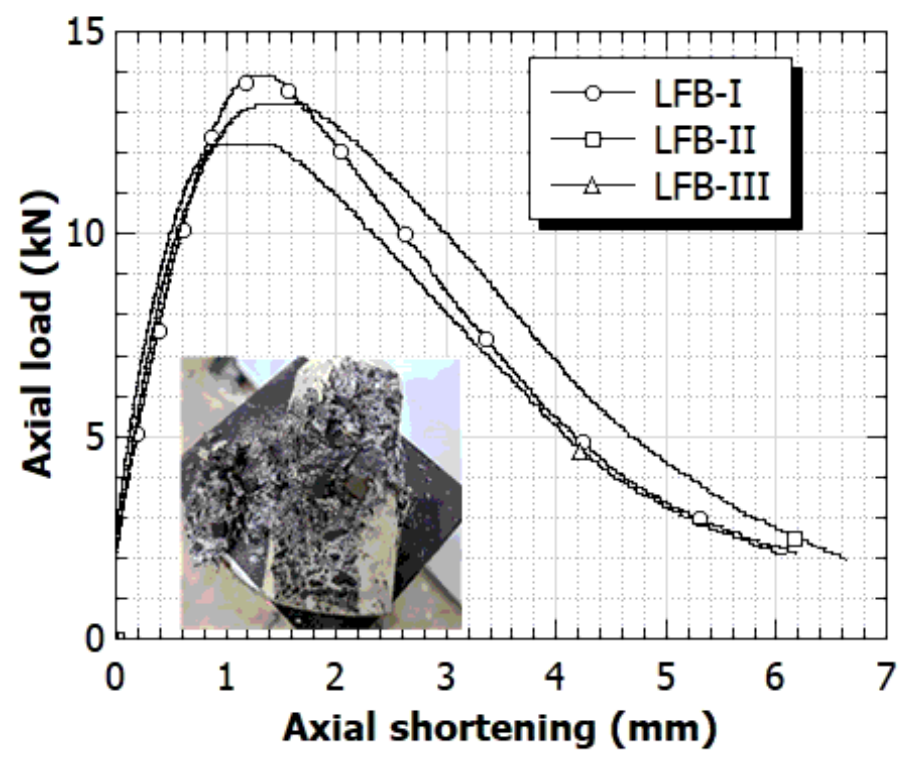

Figure 6

Axial load-axial shortening curves of F LFB specimens 


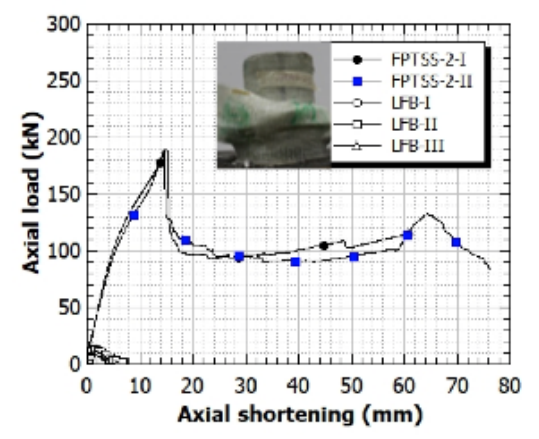

(a)

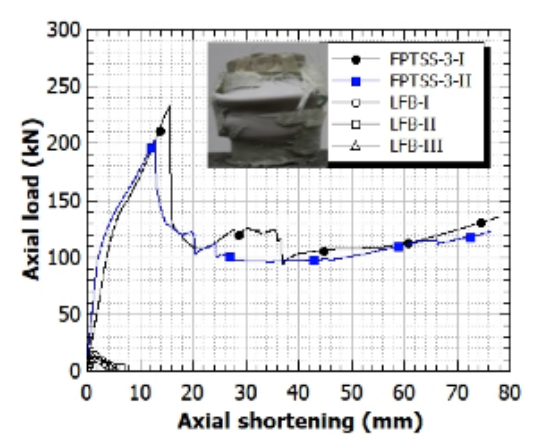

(b)

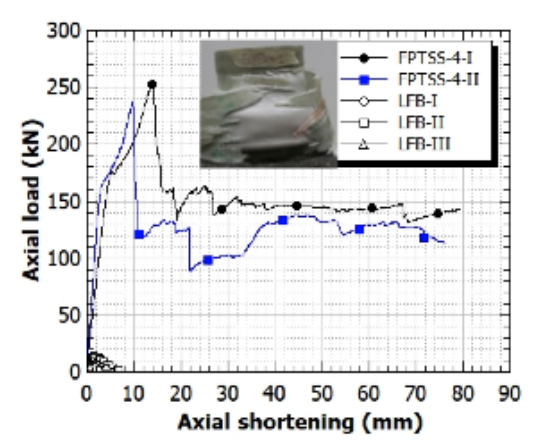

(c)

Figure 7

Axial load-axial shortening curves of FPTSS specimens 


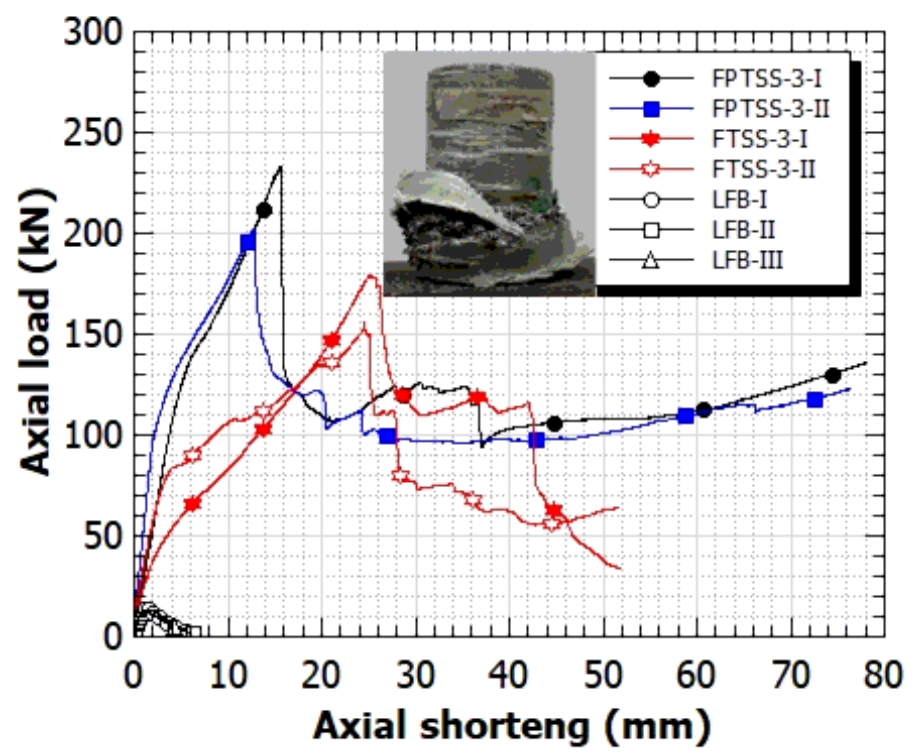

Figure 8

Comparison between FPTSS and FTSS specimens: axial load-axial shortening curves

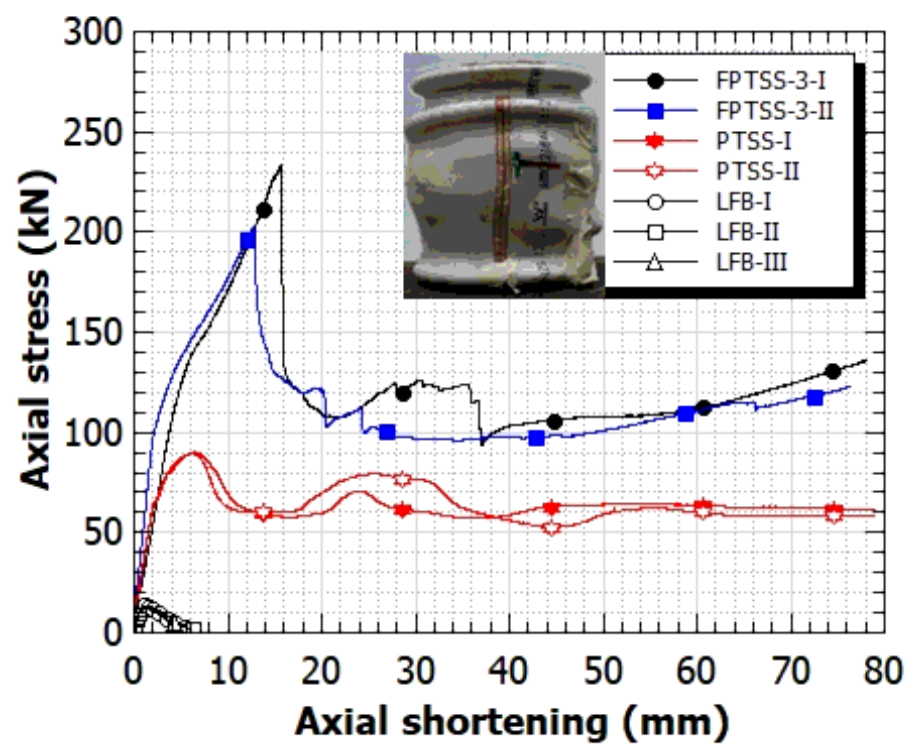

Figure 9

Comparison between FPTSS and PTSS specimens: axial load-axial shortening curves 